Retraction

\title{
Retracted: Spatial Crowdsourcing Quality Control Model Based on K-Anonymity Location Privacy Protection and ELM Spammer Detection
}

\section{Mobile Information Systems}

Received 15 May 2019; Accepted 15 May 2019; Published 27 June 2019

Copyright (c) 2019 Mobile Information Systems. This is an open access article distributed under the Creative Commons Attribution License, which permits unrestricted use, distribution, and reproduction in any medium, provided the original work is properly cited.

At the request of the authors, the article titled "Spatial Crowdsourcing Quality Control Model Based on K-Anonymity Location Privacy Protection and ELM Spammer Detection" [1] has been retracted. The authors found in a recent experiment that a serious error was caused by the server hardware failure, so the paper was written based on incorrect data and there was a big deviation in the argument.

\section{References}

[1] M. Zeng, Z. Cheng, X. Huang, and B. Zheng, "Spatial crowdsourcing quality control model based on K-anonymity location privacy protection and ELM spammer detection," Mobile Information Systems, vol. 2019, Article ID 2723686,

10 pages, 2019. 